\title{
Correlation of two validated methods for the quantification of naringenin in its solid dispersion: HPLC and UV spectrophotometric methods
}

\author{
Durgesh K. Jha ${ }^{1}$ - Devanshi S. Shah ${ }^{1} \cdot$ Shwetal R. Talele ${ }^{1}$ Purnima D. Amin ${ }^{1}$ (I)
}

Received: 13 February 2020 / Accepted: 14 March 2020 / Published online: 18 March 2020

(c) Springer Nature Switzerland AG 2020

\begin{abstract}
A UV spectrophotometric and RP-HPLC method for the Naringenin quantification in the developed solid dispersions is described. Both the methods were validated according to ICH Q2 R (1) guidelines for linearity, accuracy, precision, limit of detection, limit of quantification, specificity and robustness. HPLC was run in isocratic mode on a reversed-phase C18 column $(250 \times 4.6 \mathrm{~mm}$ internal diameter and particle size of $5 \mu \mathrm{m})$ with methanol:water $(70: 30, \mathrm{v} / \mathrm{v})$ as the mobile phase maintaining a flow rate of $1.0 \mathrm{ml} / \mathrm{min}$. Naringenin showed an absorbance maximum $\left(\lambda_{\max }\right)$ at $288 \mathrm{~nm}$ which was used for the UV spectrophotometric determinations. The calibration curve of Naringenin showed linearity in the required concentration range $\left(R^{2}>0.999\right)$ by both the UV and HPLC methods. Both the methods were found to be precise and accurate with recovery range of $98-101 \%$ and relative standard deviation $<2 \%$. Most importantly, the accuracy and precision achieved by the HPLC method, correlated closely with the UV method. Current study also involves detection and quantification of Naringenin released from its formulations by both the developed methods. This paper demonstrates the high correlation $\left(R^{2} \geq 0.98\right)$ between the UV and HPLC methods when determining the release of Naringenin from various formulations. With this established correlation, we hereby suggest that, for routine analysis, UV spectroscopy can be an economic, simple, reliable and less time-consuming alternative for expensive and time-consuming chromatographic analysis.
\end{abstract}

Keywords Naringenin $\cdot$ UV spectroscopy $\cdot$ RP-HPLC method · Validation · Solid dispersion · Correlation

\section{Introduction}

Naringenin (NRG) (Fig. 1) is a low molecular weight $(272.253 \mathrm{~g} / \mathrm{mol})$ citrus flavanone found in oranges, grapes, etc., [1] having a low solubility in water $(46 \pm 6 \mu \mathrm{g} / \mathrm{ml})[2]$. Upon ingestion, NRG gets hydrolyzed to its aglycone, Naringin, by the gut flora before it is absorbed into the system $[3,4]$. NRG has antioxidant property which is largely explored in pharmaceutical applications [5-8]. It acts as an anti-tumor [9] anti-inflammatory [10], anti-hyperlipidemic agent [11]. It is a microsomal triglyceride transfer protein inhibitor (MTP) along with acyl CoA: cholesterol acyltransferase (ACAT) inhibitor [12] and it regulates cytochrome P450 (CYP450) enzymes [13-15]. It exhibits anti-atherosclerotic activity [16]. It has shown the inhibitory action to production of hepatitis $C$ virus $[17,18]$, and block insulin resistance $[19,20]$. Despite its wide therapeutic potential, NRG's clinical role has been hindered due to its its low solubility, hence poor bioavailability and a considerable pre-systemic metabolism. A promising approach to overcome this, is the preparation of Solid Dispersion (SD) to increase the aqueous solubility and dissolution rate and further, to enhance oral bioavailability [21, 22]. In this work, solid dispersions of NRG with Poloxamer 188 and

Purnima D. Amin, purnima.amin@yahoo.co.in | ${ }^{1}$ Department of Pharmaceutical Sciences and Technology, Institute of Chemical Technology, Matunga 400019, India. 


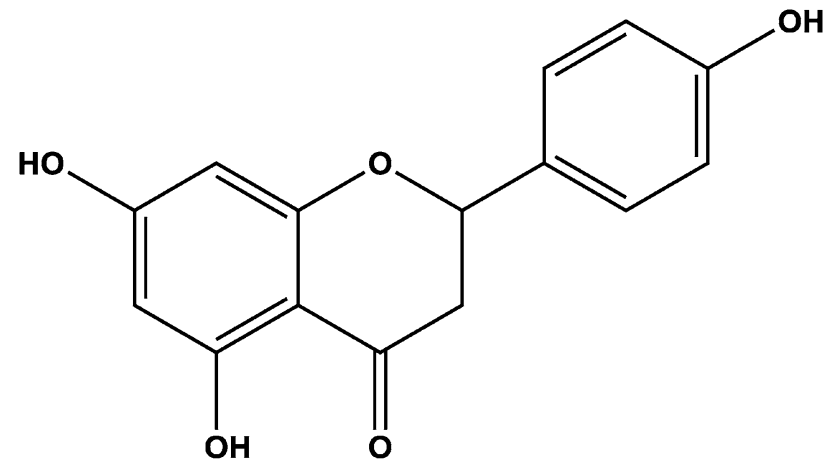

Molecular Weight: 272.26

Fig. 1 Chemical structure of Naringenin

Gelucire $^{\circledast} 48 / 16$ were prepared by the simple melt fusion method.

To determine the content of NRG and its release from these solid dispersions, it is necessary to have a simple, specific, fast and validated analytical method. Previous publications have described HPLC, [23, 24] and liquid chromatography-tandem mass spectroscopy $[25,26]$ methods for quantification of NRG in human plasma and pharmaceutical dosage forms [27]. But these methods involve extensive sample preparation procedures, and long chromatographic runs which involve a certain set of conditions to be maintained. Also, mobile phases containing certain compounds such as o-phosphoric acid, n-hexane, trifluoracetic acid, ammonium acetate, etc, may affect the column life span. Many reported methods involve the use of an internal standard which is usually difficult to procure. Hence, a modified HPLC method is developed in this work, which uses simple solvents as mobile phase without the addition of internal standards or other organic modifiers.

Despite the simplicity of the developed method, HPLC has certain disadvantages such as it is time consuming. Moreover, certain level of expertise is also required to handle such complex, sophisticated instruments. Hence, a simple, specific, accurate, precise and a reproducible UV method for the quick estimation of NRG would be highly beneficial for routine analysis of NRG. A UV Spectrophotometric method is an easy and efficient method, which provides a quick analysis of the compounds. Currently, there is a lack of information regarding UV spectroscopy method for quantitative determination of NRG in dosage form. Herein, the method developed is, one using methanol as a solvent as NRG is insoluble in water. The developed method was optimized and validated as per the guidelines given by International Conference on Harmonization (ICH) guidelines. This study also demonstrates the linearity, accuracy and robustness of the proposed method for the estimation of NRG in prepared
Table 1 Solid dispersion batch codes

\begin{tabular}{lclll}
\hline Code & $\%$ w/w NRG & \multicolumn{2}{l}{$\%$ Pw/w Carrier } & Processing \\
\cline { 3 - 4 } & \multicolumn{5}{c}{$\%$ w/w POX } & $\%$ w/w GEL \\
\hline N & 100 & - & - & - \\
NP1 & 20 & 80 & - & Melt fusion \\
NP2 & 30 & 70 & - & Melt fusion \\
NP3 & 50 & 50 & - & Melt fusion \\
NP4 & 80 & 20 & - & Melt fusion \\
NG1 & 10 & - & 90 & Melt fusion \\
NG2 & 20 & - & 80 & Melt fusion \\
NG3 & 50 & - & 50 & Melt fusion \\
NG4 & 80 & - & 20 & Melt fusion \\
PM1 & 20 & 80 & - & Physical mixture \\
PM2 & 20 & - & 80 & Physical mixture \\
\hline
\end{tabular}

solid dispersions. The objective of this study is to correlate the two NRG determination methods; UV-spectroscopy and HPLC analysis. Based on the established correlation, we propose the use of UV-spectroscopic method as a simple method for quantification of NRG.

\section{Materials and methods}

\subsection{Materials}

Naringenin (NRG) pure (min. 95\%) was obtained from Sigma-Aldrich, India. Poloxamer 188 (POX) was gifted by BASF, India. Gelucire ${ }^{\circledR} 48 / 16$ (GEL) was obtained as a gift sample from Gattefosse, India. Gangwal Chemicals, Mumbai gifted Neusilin US 2 (NSL) (Fuji Chemical Industry. (o. Ltd) was obtained as a gift sample from Gangwal. All other chemicals and reagents used were of analytical grade. Milli-Q water was obtained by the Millipore system (Moslheim France).

\subsection{Preparation of solid dispersions}

Solid dispersions of NRG were prepared using POX and GEL as the solubilizer in the ratios as shown in Table 1 and NSL was used as an adsorbent. Initially, weighed amounts of POX and GEL were heated at $120^{\circ} \mathrm{C}$ to give a complete melt to which, NRG was added and dissolved completely till a transparent yellowish, oily liquid product was obtained. This mixture was then plated on adsorbent NSL to render a free-flowing powder. Physical mixtures of NRG with POX (PM 1) and GEL (PM 2) were prepared by mortar and pestle for comparative analysis with the SDs. 


\subsection{Preparation of standard solutions}

\subsubsection{Preparation of standard solution for UV spectroscopy}

$10 \mathrm{mg}$ of pure NRG was weighed accurately and transferred to a $10 \mathrm{ml}$ volumetric flask. Methanol was used to make up to the final volume of $10 \mathrm{ml}$, to make a concentration of $1000 \mu \mathrm{g} / \mathrm{ml}$. From the above solution, $1 \mathrm{ml}$ was transferred to another $10 \mathrm{ml}$ volumetric flask. Methanol was used to make up the volume to $10 \mathrm{ml}$. A standard stock solution of $100 \mu \mathrm{g} / \mathrm{ml}$ was prepared for the UV spectroscopic analysis. From this primary stock solution, working standards of concentration from 2 to $12 \mu \mathrm{g} / \mathrm{ml}$ was prepared for UV Spectroscopic analysis.

\subsubsection{Preparation of standard solution for HPLC}

$10 \mathrm{mg}$ of pure NRG was weighed accurately and transferred to a $10 \mathrm{ml}$ volumetric flask. Methanol was used as the diluting solvent to make up to the final volume of $10 \mathrm{ml}$, to make a concentration of $1000 \mu \mathrm{g} / \mathrm{ml}$. This was used as the primary stock solution of NRG from which working standards of concentrations from 2.5 to $100 \mu \mathrm{g} /$ $\mathrm{ml}$ was prepared for HPLC analysis.

\subsection{Determination of the wavelength}

Appropriate $1 \mathrm{ml}$ of the standard stock solution was taken in a $10 \mathrm{ml}$ volumetric flask. It was further diluted using methanol to give a concentration of $10 \mu \mathrm{g} / \mathrm{ml}$. This solution was scanned via UV Spectroscopy through the range of 200-800 nm for the determination of the wavelength of maximum absorption by NRG $\left(\lambda_{\text {max }}\right)$. Similarly, the $10 \mu \mathrm{g} /$ $\mathrm{ml}$ of POX and GEL were made and scanned through the range of 200-800 $\mathrm{nm}$ to observe their interferences on the quantification of NRG.

\subsection{Instrumentational and analytical conditions}

High performance liquid Chromatography (HPLC) system

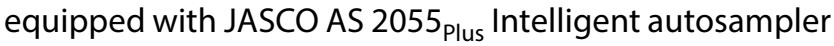

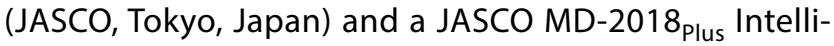
gent HPLC pump. It consists of a Quaternary pump, Photo Diode array detector, and a rheodyne injection valve with a $100 \mu \mathrm{L}$ loop with an online degasser. ChromNAV software program was used to calculate all the peak areas. The optimum chromatographic conditions were obtained on a Syncronis $C 18,250 \times 4.6 \mathrm{~mm}$ and particle size $5 \mu \mathrm{m}$ column (ThermoScientific technologies). The mobile phase composition was a 70:30 v/v ratio of Methanol and Milli$\mathrm{Q}$ water. It was filtered through $0.45 \mu \mathrm{m}$ nylon filter and sonicated (Enertech fast ultrasonicate cleaner, Mumbai) for $20 \mathrm{~min}$. Wavelength was set at $\lambda_{\max }$ of NRG. The mobile phase was pumped at a flow rate $1 \mathrm{ml} / \mathrm{min}$ with $20 \mu \mathrm{l}$ injection volume. All experiments were carried out at temperature of $25 \pm 2{ }^{\circ} \mathrm{C}$ and the total area of drug peak was used to quantify NRG. These conditions were optimized to provide a simple and reliable method with the best peak resolution for symmetry, tailing, and reduced run time and lower the cost of analysis. All experiments were performed in the isocratic mode and in triplicates. The chromatographic conditions are tabulated in the Table 2.

UV spectroscopic analysis was carried out using the UV spectrophotometer (Labman Scientific Instruments, Imdia). Absorbance was measured using $1 \mathrm{~cm}$ quartz cell against a blank sample.

\subsection{Method validation}

\subsubsection{System suitability}

Freshly prepared standard stock solutions of NRG were used for system suitability tests. The standard deviation is calculated by injecting $100 \mu \mathrm{g} / \mathrm{ml}$ of NRG standard solution for six times at short regular time intervals. The peak areas were recorded under optimum chromatographic conditions to evaluate the system suitability. The percent coefficient of variation ( $\% \mathrm{CV}$ ) of $\leq 2 \%$ for the peak area and retention times for NRG was set as the acceptance criterion.

\subsubsection{Linearity}

The potential of an analytical procedure to generate results which are in direct proportion to the analyte concentration within a given range is termed as linearity, and it is measured from the regression coefficient of the graph. At least, five concentration levels or working standards, along with certain minimum specified ranges are required. Six aliquots of NRG working standard solutions were prepared

Table 2 Chromatographic conditions

\begin{tabular}{ll}
\hline HPLC unit & Jasco system \\
\hline Column & $\begin{array}{c}\text { Synchronis-C18, }(250 \times 4.6 \mathrm{~mm}) \\
\text { packed with } 5 \mu \mathrm{m} \text { particles } \\
\text { (ThermoScientific) } \\
\text { Photodiode Detector (Jasco MD- } \\
\text { 2018 }{ }_{\text {Plus }} \text { ) }\end{array}$ \\
Metector & Methanol: Mili-Q Water (70:30) \\
Dobile phase & 288 \\
Run time (minutes) & 10 \\
Flow rate (ml/min) & 1.0 \\
Volume of injection loop $(\mu \mathrm{L})$ & 20 \\
Elution mode & Isocratic \\
Column temperature & Ambient \\
\hline
\end{tabular}


from the standard stock solution of concentration $100 \mu \mathrm{g} /$ $\mathrm{ml}$ in range from 2 to $12 \mu \mathrm{g} / \mathrm{ml}$ for UV analysis. Methanol was used to make up the volume to $10 \mathrm{ml}$. For HPLC analysis, six aliquots of concentration range $2.5-100 \mu \mathrm{g} / \mathrm{ml}$ were prepared. They were scanned at $\lambda_{\max }$ of NRG. The calibration plot was constructed as concentration vs absorbance/ peak area. The least square regression method was used to evaluate linearity from the obtained data.

\subsubsection{Limit of detection (LOD) and limit of quantification (LOQ)}

The lowest amount of analyte that the analytical method can dependably differentiate from the background noise levels is termed as the limit of detection. On the other hand, the lowest concentration on linearity curve which can be measured accurately and with precision and variability, is termed as the limit of quantification.

Limit of detection and quantification was determined from the standard deviation of the intercept and slope of the calibration curve, as per ICH guidelines Q2 (R1) as shown in Eqs. $(1,2)$.

$L O D=3.3 \times \sigma / S$

$L O Q=10 \times \sigma / S$

where $\sigma=$ a standard deviation of $y$-intercept; $S=$ slope of the calibration plot.

\subsubsection{Intra-day and inter-day precision studies}

Precision of an analytical method can be defined as the degree of repeatability under normal operational conditions. Precision of the method was carried out by determining the repeatability (intra-day) and intermediate precision (inter-day) of the samples and \%RSD was reported for replicate measurements. Intraday was determined by analyzing the samples thrice a day by UV Spectroscopy and HPLC at different time intervals. Inter-day studies were carried out by preparing and analyzing the aliquot solutions prepared from different stock solutions on three consecutive days.

\subsubsection{Accuracy and recovery}

The accuracy of an analytical method is the agreement between the true value and the value found (i.e., exactness of any method). The analyte percentage recovered by assay of a known amount is termed as accuracy. Accuracy of the developed analytical method was determined by analyzing the added analytes in the pre-analyzed samples matrix at three different levels (50\%, 100\% and 150\%) and calculated in terms of \% recovery of NRG from the spiked samples. The newly prepared samples were analyzed as per the developed method.

\subsubsection{Robustness}

Robustness of the above method was determined by deliberately changing one parameter at a time while keeping the others constant. The study was carried out by varying the wavelength in the range of $\lambda_{\max } \pm 2 \mathrm{~nm}$ and the concentration of standard NRG solutions between 9.8 and $10.2 \mu \mathrm{g} / \mathrm{ml}$ while keeping other parameters constant in case of UV Spectrophotometry. For HPLC validation, small deliberate changes in the analytical conditions such as mobile phase composition $(70 \pm 2 \mathrm{ml}: 30 \pm 2 \mathrm{ml})$, flow rate $(1 \pm 0.1 \mathrm{ml} / \mathrm{min})$, and detection wavelength $( \pm 2 \mathrm{~nm})$ were made. The effect of these deliberate changes on the retention time and peak area was evaluated. The RSDs of retention times and peak areas were calculated for each parameter.

\subsubsection{Specificity}

The effect of excipients used in the preparation of solid dispersion was checked. The specificity for both, HPLC and UV methods was determined. The specificity was evaluated by analysis of placebos batches, wherein the sample without NRG was analyzed. The system response was examined.

\subsubsection{Assay of developed solid dispersions of NRG}

Assay of the prepared solid dispersions of NRG was calculated using both the methods. A $10 \mathrm{mg}$ equivalent of NRG was weighed from the formulation. Then, $10 \mu \mathrm{g} / \mathrm{ml}$ of NRG solution was prepared, and it was quantified according to the UV and HPLC method developed. The experiment was performed in triplicates.

\subsection{Release study}

For dissolution studies, NRG $(30 \mathrm{mg})$ and its solid dispersions equivalent to $30 \mathrm{mg}$ NRG were weighed and filled in hard gelatin capsules. The physical mixture and the solid dispersions were investigated for their dissolution behavior on USP dissolution apparatus II with sinkers (Electrolab Mumbai, India), in a dissolution media of $1000 \mathrm{~mL}$ water at $37 \pm 0.5^{\circ} \mathrm{C}$ at a speed of $100 \mathrm{rpm}$. NRG dissolved up to 2 $\mathrm{h}$ from solid dispersion, physical mixtures and pure form was determined by UV and HPLC methods.

Correlation was determined on the data of NRG release obtained by UV-Spectroscopy and HPLC method. Linear regression method was used to measure the 
strength of the association $\left(R^{2}\right)$ between the two methods. The HPLC release data on the Y-axis is plotted against the corresponding UV data X-axis. The correlation coefficient $\left(R^{2}\right)$ is calculated to estimate the degree of association between these two variables.

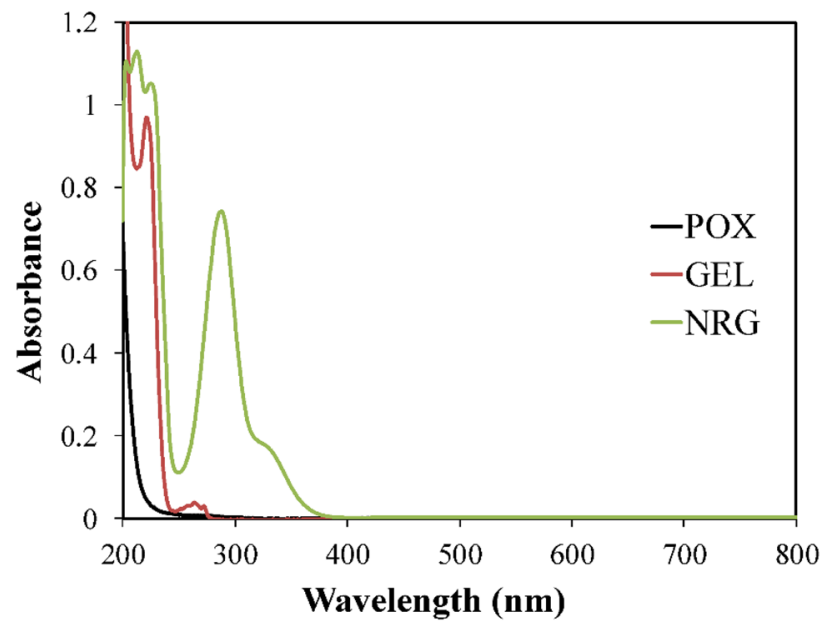

Fig. 2 UV Spectrum of NRG, Gelucire 48/16 and Poloxamer 188 from 200 to $800 \mathrm{~nm}$
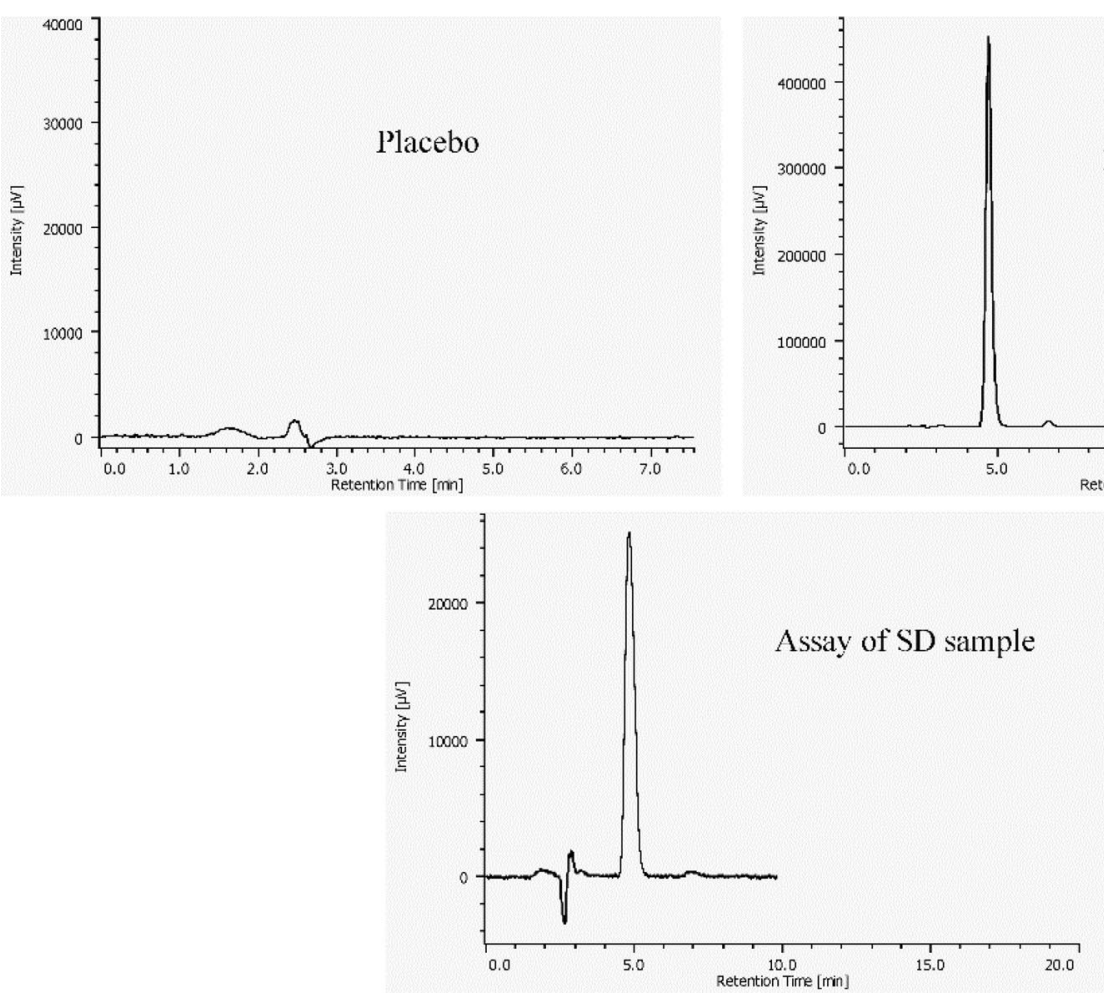

\section{Results and discussion}

\subsection{Method development}

NRG shows very low solubility in water and is found to be easily soluble in methanol. Hence, methanol was used as a solvent for analysis. The wavelength of maximum absorption after scanning was found to be $288 \mathrm{~nm}$ (Fig. 2). Figure 3 depicts the chromatograms obtained for the analyzed standard and sample solution of NRG using the developed method. As shown in Fig. 3, NRG eluted well and showed separation from the solvent front. The retention time of $4.7 \mathrm{~min}$ provided a faster determination.

\subsection{HPLC system suitability}

Results of six replicate analysis of $100 \mu \mathrm{g} / \mathrm{ml}$ concentration for the system suitability studies were in acceptable range. The \%RSD was found to be 1.4 and 0.85 for peak area and retention time, respectively as shown Table 3 . NRG was repeatedly well eluted at 4.7 min expressing excellent suitability and a good repeatability of replicate sample analysis. Thus, it can be inferred that the developed method is suitable for NRG analysis.

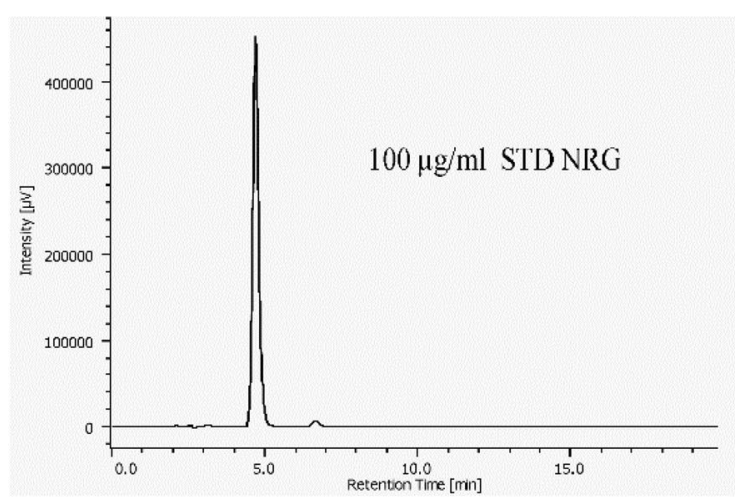

Fig. 3 Chromatograms showing the specificity of HPLC method 
Table 3 HPLC system suitability study

\begin{tabular}{lll}
\hline Concentration $(\mu \mathrm{g} / \mathrm{ml})$ & Peak area & $\begin{array}{l}\text { Retention } \\
\text { time }(\mathrm{min})\end{array}$ \\
\hline 100 & $6,146,443$ & 4.7 \\
& $6,034,111$ & 4.8 \\
& $6,149,538$ & 4.7 \\
& $6,063,716$ & 4.69 \\
& $6,317,458$ & 4.78 \\
& $6,175,766$ & 4.68 \\
Average & $6,147,839$ & 4.7 \\
SD & 90,890 & 0.04 \\
\%RSD & 1.4 & 0.85 \\
\hline
\end{tabular}

\subsection{Method validation}

The UV and HPLC method developed was validated for Linearity, Inter-day and Intra-day studies, Stability, Accuracy, Recovery, Robustness, Ruggedness and Specificity according to the guidelines set by the International Conference of Harmonization (ICH).

\subsubsection{Linearity}

The calibration curve showed a good linear relation over the concentration range of $2-12 \mu \mathrm{g} / \mathrm{ml}$ for UV Spectrophotometry and between 2.5 and $100 \mu \mathrm{g} / \mathrm{ml}$ for HPLC analysis. The linear equation was found to be $y=0.072 \times$ for UV spectrometry while $y=59549 x+146,935$ for HPLC. The correlation coefficient was found to be 0.9992 and 0.997 for UV and HPLC, respectively. The calibration curve is depicted in Figs. 4 and 5 for UV and HPLC respectively, and the results of the linearity study is depicted in Table 4 for UV Spectroscopy for HPLC. Figure 6 depicts the linearity overlay of the working standards.

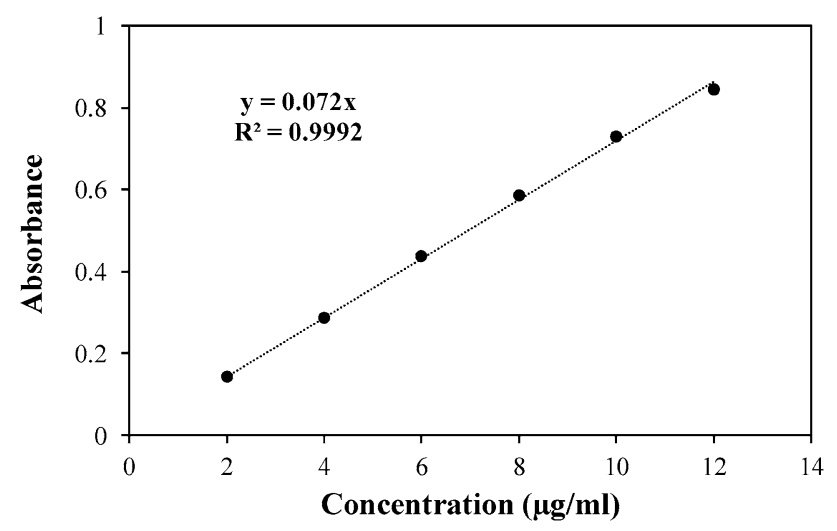

Fig. 4 Calibration curve of naringenin over concentration of $2-12 \mu \mathrm{g} / \mathrm{ml}$

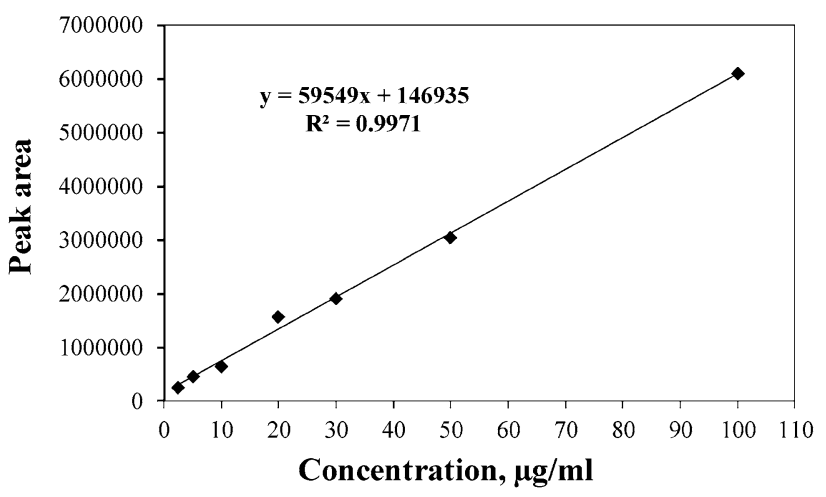

Fig. 5 HPLC calibration curve of naringenin over concentration of $2.5-100 \mu \mathrm{g} / \mathrm{ml}$

\subsubsection{LOD and LOQ}

The LOD and LOQ were calculated and are shown in Table 4 for UV and HPLC method. The relative standard deviation of the intercept and the slope of the regression line is used to calculate the LOD and LOQ values. Estimated LOD and LOQ values for UV method was $0.52 \mu \mathrm{g} / \mathrm{mL}$ and $1.59 \mu \mathrm{g} /$ $\mathrm{ml}$, respectively, while that calculated for the HPLC method was $0.063 \mu \mathrm{g} / \mathrm{mL}$ and $0.19 \mu \mathrm{g} / \mathrm{mL}$, respectively. The LOQ and LOD concentrations, as calculated, assured that the methods were sensitive enough. Precisely, HPLC method was found to be more sensitive than UV.

\subsubsection{Inter-day and intra-day studies}

The results of both intra-day and inter-day studies confirm a high precision and repeatability of the developed methods. All data is expressed in RSD\% ( $\leq 2 \%)$. The results for the Intra-day and Inter-day studies for both, UV and HPLC methods are as demonstrated in Table 5. It was found that $\%$ RSD for intra-day and inter-day precision studies for HPLC method was 1.07 and 0.36 , respectively, whereas that for the UV method was 0.38 and 0.97 , respectively.

\subsubsection{Accuracy and recovery}

The average recovery for each spiked level was been calculated by the peak area of NRG resulting from the solution to that of the standard solution. Both the methods revealed the accuracy with the recovery rate between 99 and $101 \%$. The result of the study is reported in Table 6.

\subsubsection{Robustness}

The robustness of HPLC method was established by making deliberate changes in the three parameters (Table 7). The three parameters viz. mobile phase ratio, flow rate 
Table 4 Linear regression data for the calibration curve $(n=3)$ HPLC and UV

\begin{tabular}{|c|c|c|c|c|}
\hline \multirow[t]{2}{*}{ Parameter } & \multicolumn{2}{|l|}{ HPLC } & \multicolumn{2}{|l|}{ UV } \\
\hline & Mean \pm SD & $\%$ RSD & Mean \pm SD & $\% \mathrm{RSD}$ \\
\hline Linearity range & $2.5-100 \mu \mathrm{g} / \mathrm{ml}$ & - & $2-12 \mu \mathrm{g} / \mathrm{ml}$ & - \\
\hline Correlation coefficient $\left(\mathrm{R}^{2}\right)$ & $0.997 \pm 0.00057$ & 0.057 & $0.9992 \pm 0.007$ & 0.76 \\
\hline Slope & $59,549 \pm 633.7$ & 1.06 & $0.072 \pm 0.0012$ & 1.67 \\
\hline Intercept & $146,935 \pm 11,314$ & 7.7 & $0.016 \pm 0.0115$ & 6.9 \\
\hline LOD & $0.063278 \mu \mathrm{g} / \mathrm{ml}$ & & $0.52 \mu \mathrm{g} / \mathrm{ml}$ & \\
\hline LOQ & $0.191752 \mu \mathrm{g} / \mathrm{ml}$ & & $1.59 \mu \mathrm{g} / \mathrm{ml}$ & \\
\hline
\end{tabular}

Fig. 6 Linearity overlay

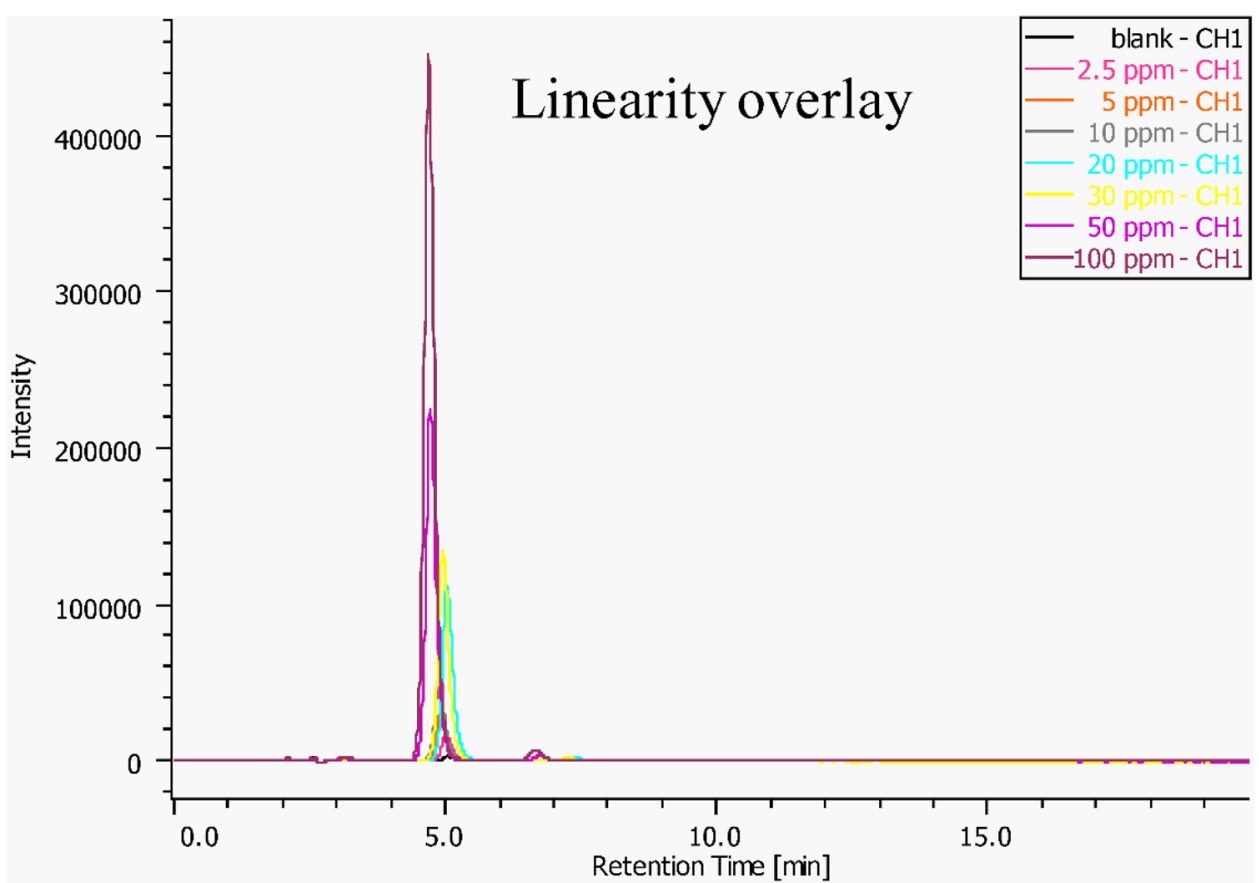

Table 5 Repeatability (Intraday) and intermediate (Interday) precision of HPLC and UV method $(n=3)$

\begin{tabular}{|c|c|c|c|c|c|c|c|c|}
\hline \multirow{3}{*}{$\begin{array}{l}\text { Concentra- } \\
\text { tion }(\mu \mathrm{g} / \\
\mathrm{ml})\end{array}$} & \multicolumn{4}{|l|}{ HPLC } & \multicolumn{4}{|l|}{ UV } \\
\hline & \multicolumn{2}{|l|}{ Repeatability } & \multicolumn{2}{|l|}{ Intermediate precision } & \multicolumn{2}{|l|}{ Repeatability } & \multicolumn{2}{|l|}{ Intermediate precision } \\
\hline & Mean peak area \pm SD & $\%$ RSD & Mean peak area \pm SD & $\% \mathrm{RSD}$ & Mean absorbance \pm SD & \%RSD & Mean absorbance \pm SD & $\%$ RSD \\
\hline 100 & $6,110,031 \pm 65,767$ & 1.07 & $6,135,337 \pm 21,971$ & 0.36 & - & - & - & - \\
\hline 10 & - & - & - & - & $0.733 \pm 0.003$ & 0.386 & $0.731 \pm 0.007$ & 0.97 \\
\hline
\end{tabular}

and the detection wavelength were varied at 3 levels. The $\%$ RSD for all the three parameters at all the three levels was found to be less than $2 \%$. Thus, it can be concluded that the developed HPLC method is robust with respect to these three parameters.

The data for robustness of the UV method are specified in Table 8. At a constant concentration of $10 \mu \mathrm{g} / \mathrm{ml}$, the small change in the wavelength range $288 \pm 2 \mathrm{~nm}$, did not show any significant change in the absorbance
(\%RSD $=0.821)$. This suggests that the above method is robust with respect to wavelength. Hence, a slight variation in the wavelength does not affect the results. On measuring the absorbance at a constant wavelength $(288 \mathrm{~nm})$ and changing the concentration from 9.8 to $10.2 \mu \mathrm{g} / \mathrm{ml}$, the \% RSD was found to be 4.080 . A slight change in concentration drastically affects the absorbance. 
Table 6 Recovery data for the accuracy of the HPLC and UV method $(n=3)$

\begin{tabular}{|c|c|c|c|c|c|}
\hline $\begin{array}{l}\text { Excess of Naringenin } \\
\text { added (\%) }\end{array}$ & $\begin{array}{l}\text { Pre-analyzed } \\
\text { sample }(\mu \mathrm{g})\end{array}$ & $\begin{array}{l}\text { Theoretical concentration of } \\
\text { spiked sample }(\mu \mathrm{g})\end{array}$ & $\begin{array}{l}\text { Measured concentration of } \\
\text { spiked sample }(\mu \mathrm{g})\end{array}$ & Recovery \pm SD (\%) & $\% \mathrm{RSD}$ \\
\hline \multicolumn{6}{|l|}{ HPLC } \\
\hline 50 & 100 & 150 & 149.48 & 99.65 & 1.6 \\
\hline 100 & 100 & 200 & 202.12 & 101.06 & 1.32 \\
\hline 150 & 100 & 250 & 249.98 & 99.99 & 1.52 \\
\hline \multicolumn{6}{|l|}{ UV } \\
\hline 50 & 10 & 15 & 14.93 & 99.5 & 1.763 \\
\hline 100 & 10 & 20 & 19.8 & 99 & 1.406 \\
\hline 150 & 10 & 25 & 25.2 & 100.8 & 1.582 \\
\hline
\end{tabular}

Table 7 Robustness data of the HPLC method

\begin{tabular}{|c|c|c|c|c|c|c|}
\hline \multirow[t]{2}{*}{ Parameter } & \multicolumn{2}{|c|}{ Study condition } & \multirow[t]{2}{*}{ Mean area $\pm S D$} & \multirow[t]{2}{*}{$\%$ RSD of area } & \multirow[t]{2}{*}{$\mathrm{R}_{\mathrm{t}} \pm \mathrm{SD}$} & \multirow[t]{2}{*}{$\% R S D$ of $R_{t}$} \\
\hline & original & varied & & & & \\
\hline \multirow[t]{3}{*}{ Mobile phase ratio (MeOH/Water) } & $70: 30$ & $68: 32$ & $6,094,750 \pm 49,858.25$ & 0.82 & $4.85 \pm 0.066$ & 1.37 \\
\hline & & $70: 30$ & & & & \\
\hline & & $72: 28$ & & & & \\
\hline \multirow[t]{3}{*}{ Flow rate $(\mathrm{ml} / \mathrm{min})$} & 1.0 & 0.9 & $5,966,773 \pm 58,757.11$ & 0.98 & $4.77 \pm 0.0057$ & 0.12 \\
\hline & & 1.0 & & & & \\
\hline & & 1.1 & & & & \\
\hline \multirow[t]{3}{*}{ Detection wavelength } & 289 & 287 & $6,089,915 \pm 47,651.19$ & 0.81 & $4.68 \pm 0.00$ & 0.001 \\
\hline & & 289 & & & & \\
\hline & & 291 & & & & \\
\hline
\end{tabular}

$\mathrm{n}=3$ at each level

Concentration $=100 \mu \mathrm{g} / \mathrm{ml}$

Table 8 Robustness of the UV method $(n=3)$

\begin{tabular}{llll}
\hline $\begin{array}{l}\text { Constant parameter } \\
\text { Concentration }\end{array}$ & $\begin{array}{l}\text { Variable parameter } \\
\text { Wavelength }(\mathrm{nm})\end{array}$ & Absorbance & $\begin{array}{l}\text { Average absorbance } \\
(\text { Mean } \pm \text { SD })\end{array}$ \\
\hline $10 \mu \mathrm{g} / \mathrm{ml}$ & 286 & 0.738 & \\
& 287 & 0.744 & 0.822 \\
& 288 & 0.731 & $0.737 \pm 0.006$ \\
& 289 & 0.731 & \\
\hline Wavelength & 290 & 0.742 & $($ Mean \pm SD) \\
\hline $288 \mathrm{~nm}$ & Concentration $(\mu \mathrm{g} / \mathrm{ml})$ & & $0.709 \pm 0.209$ \\
\end{tabular}

\subsubsection{Specificity}

Figure 3 shows the chromatograms for placebo sample, standard and its SD, justifying that there is no interference of the excipients in the peak of NRG. This ensures method is specific for the determination of NRG.
Similarly, placebo samples were analyzed using UV method to check the absorbance of the excipients at the $\lambda_{\max }$ of NRG. Interestingly, it was found that the placebo samples showed negligible absorbance at $288 \mathrm{~nm}$ as shown in Fig. 2. This might be due to the absence of chromophores in the POX and GEL, which absorb at that 
wavelength. Here, it is important to note that there was no interference of POX and GEL which are excipients in this formulation, but this may not be the same for every other excipient. Hence, the interference must be checked if the formulation is changed.

Hence, it can be inferred that the proposed UV and HPLC methods are specific, since no interference was observed with placebo sample.

\subsubsection{Assay of solid dispersions of NRG}

The UV and HPLC methods could also be used to determine the assay of NRG in raw material and SDs. Results show that NRG content in all samples lies in the range of 99.1 to $100.2 \%$ of the \%labeled amount with \%RSDs of less than $2 \%$ (Table 9). No degradation products were observed in the investigated samples. The developed formulation was quantified according to the developed methods.

\subsection{Correlation between the HPLC method and UV method for release data}

The parity plot of UV and HPLC correlation of the NRG release is shown in Fig. 7. Dissolution media for all the SDs was distilled water. The release percentage of pure NRG was found to be 22.31 by UV method and 26 by HPLC analysis at the end of $2 \mathrm{~h}$. The physical mixtures of NRG with POX (PM1) and GEL (PM2) showed a release of $31 \%$ and $56 \%$, respectively at the end of $2 \mathrm{~h}$ by UV-spectrophotometry and $29 \%$ and $52 \%$, respectively by HPLC analysis. There is a slight increase in the dissolution rate of PM compared to pure NRG. This improvement in release can be attributed to increased wettability conferred by the surfactant properties of POX and GEL, which is more in case of GEL. All the SDs showed an increased dissolution rate compared to pure NRG and their PMs. However, the dispersions with lower active loading i.e., NP1 and NG1, showed $77.31 \%$ and $78.7 \%$ NRG release by UV method by

Table 9 Assay of the SD formulations of naringenin $(n=3)$

\begin{tabular}{|c|c|c|c|c|c|}
\hline \multirow[t]{2}{*}{ Sample code } & \multirow[t]{2}{*}{$\% \mathrm{w} / \mathrm{w}$ NRG } & \multicolumn{2}{|l|}{ HPLC } & \multicolumn{2}{|l|}{ UV } \\
\hline & & Mean & $\%$ RSD & Mean $\pm S D$ & \%RSD \\
\hline NP1 & 20 & 97.35 & 2.27 & 97.012 & 1.62 \\
\hline NP2 & 30 & 103.04 & 1.57 & 96.159 & 1.7 \\
\hline NP3 & 50 & 100.23 & 8.51 & 99.3 & 7.59 \\
\hline NP4 & 80 & 98.69 & 1.44 & 101.23 & 1.35 \\
\hline NG1 & 20 & 99.23 & 1.45 & 97.35 & 2.35 \\
\hline NG2 & 30 & 101.23 & 2.25 & 98.99 & 2.04 \\
\hline NG3 & 50 & 97.23 & 1.35 & 102.35 & 1.58 \\
\hline NG4 & 80 & 98.25 & 1.89 & 100.26 & 2.05 \\
\hline
\end{tabular}

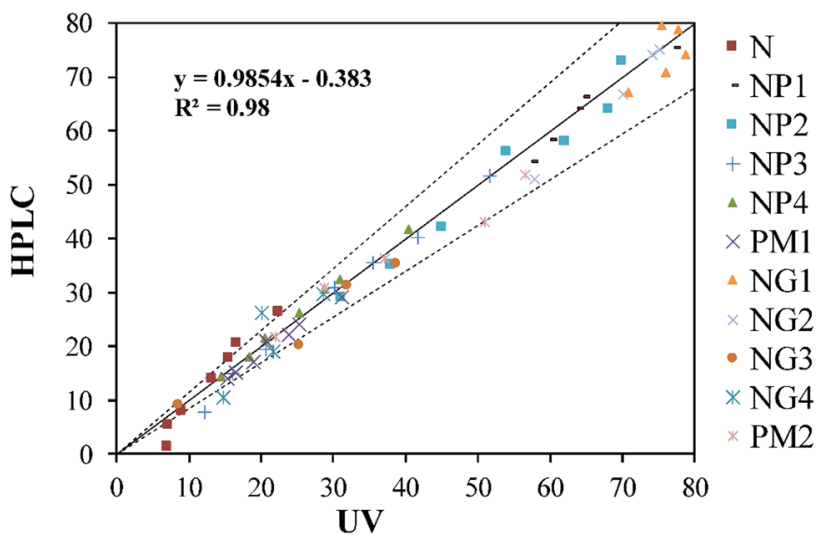

Fig. 7 Parity plot for the correlation of UV and HPLC methods

at the end of $2 \mathrm{~h}$ in a dissolution media of double distilled water, while $75.38 \%$ and $74.1 \%$ by HPLC method NRG release in the same media. This depicts that there is an increase in the dissolution rate of NRG with lower loading in both the carriers. The enhanced dissolution rate of NRG from the solid dispersions is because of the conversion of crystalline NRG to its amorphous form. Figure 8 shows the characteristic XRD peaks of pure forms of NRG, POX and GEL confirming their crystalline form which is in conjugation with the literature [28-30]. The diffractograms of SDs (NP1 and NG1) revealed a disappearance in NRG peaks, which denotes a transition from crystalline to an amorphous form; a behavior already observed for other drugs in solid dispersions [21, 31].

From the above results, the values of NRG concentration given by both the methods; UV-spectroscopy and HPLC method are in the close agreement. Parity plot of UV and HPLC values of NRG release illustrates the high correlation

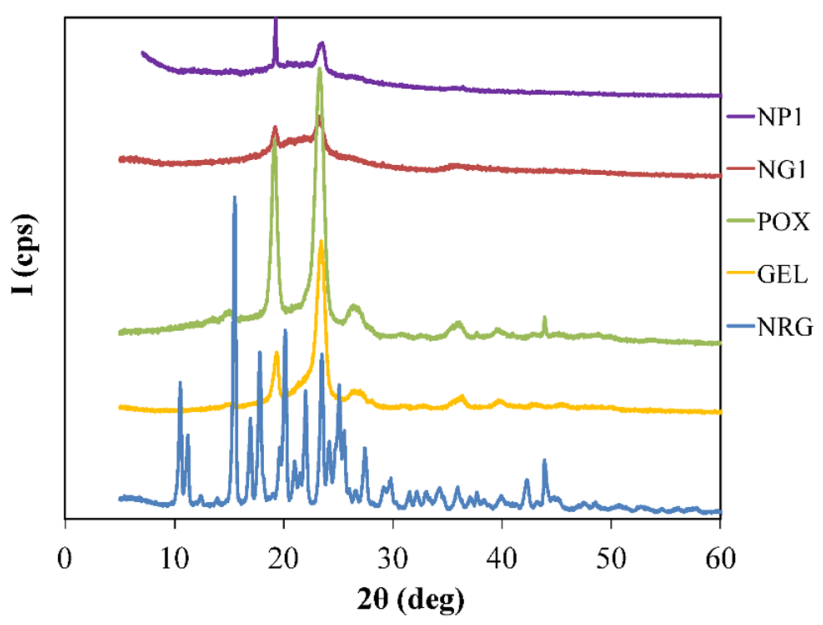

Fig. 8 XRD diffractograms 
between the two methods for quantifying NRG. The dotted lines show the $\pm 15 \%$ deviation from ideal line.

\section{Conclusions}

It can be concluded that both the methods (UV-spectroscopy and HPLC) were highly correlated for the NRG quantification from the formulations. Though HPLC is widely used to quantify the NRG, the proposed UV Spectrophotometric method of NRG was found to be simple, economic, quick, accurate and robust. The low LOD and LOQ values suggest the good sensitivity of the developed method. Moreover, the method was sensitive to concentration of the analyte as it shows a very high RSD on deliberately changing the concentration of $10 \mu \mathrm{g} / \mathrm{ml}( \pm 0.2 \mu \mathrm{g} / \mathrm{ml})$, keeping all other parameters constant. The method is robust with respect to wavelength in the range $288 \mathrm{~nm}( \pm 2 \mathrm{~nm})$. The method is specific as no other excipients from the placebo, interfered with the analyte of interest. On performing the assay of NRG formulations, the $\%$ assay was found to be within the acceptable range. The dissolution studies depict the high release of NRG from its SDs as shown by both the methods, justifying the formation of amorphous NRG. The parity plot shows high correlation $\left(R^{2}=0.98\right)$ in the results given by both the methods. Hence, UV method has been validated and according to the results and parameters, it is an appropriate method for a quick analysis of NRG in bulk and in nutraceutical formulations.

Author's contribution All the authors have contributed in designing the study. Durgesh has performed the HPLC method development, validation, and correlation study under the guidance of Purnima Amin. Durgesh, Devanshi and Shwetal have drafted the manuscript as per the journal submission format. All authors read and approved the final manuscript.

\section{Compliance with ethical standards}

Conflict of interest The authors declare that they have no conflict of interest.

Ethics approval This article does not contain any studies with human participants performed by any of the authors.

\section{References}

1. Rao VP, Kiran S, Rohini P, Bhagyasree P (2017) Flavonoid: a review on naringenin. J Pharmacogn Phytochem 6:2778-2783

2. Khan AW, Kotta S, Ansari SH et al (2015) Enhanced dissolution and bioavailability of grapefruit flavonoid naringenin by solid dispersion utilizing fourth generation carrier. Drug Dev Ind Pharm 41:772-779. https://doi.org/10.3109/03639 045.2014 .902466
3. Wilcox LJ, Borradaile NM, Huff MW (1999) Antiatherogenic properties of naringenin, a citrus flavonoid. Cardiovasc Drug Rev 17:160-178. https://doi.org/10.1111/j.1527-3466.1999.tb000 $11 . x$

4. Lee YS, Reidenberg MM (1998) A method for measuring naringenin in biological fluids and its disposition from grapefruit juice by man. Pharmacology 56:314-317. https://doi. org/10.1159/000028215

5. Jung UJ, Kim HJ, Lee JS et al (2003) Naringin supplementation lowers plasma lipids and enhances erythrocyte antioxidant enzyme activities in hypercholesterolemic subjects. Clin Nutr 22:561-568. https://doi.org/10.1016/S0261-5614(03)00059-1

6. Prabu SM, Shagirtha K, Renugadevi J (2011) Naringenin in combination with vitamins $C$ and $E$ potentially protects oxidative stress-mediated hepatic injury incadmium-intoxicated rats. J Nutr Sci Vitaminol (Tokyo) 57:177-185. https://doi.org/10.3177/ jnsv.57.177

7. Renugadevi J, Prabu SM (2009) Naringenin protects against cadmium-induced oxidative renal dysfunction in rats. Toxicology 256:128-134. https://doi.org/10.1016/j.tox.2008.11.012

8. Patel K, Singh GK, Patel DK (2018) A review on pharmacological and analytical aspects of naringenin. Chin J Integr Med 24:551560. https://doi.org/10.1007/s11655-014-1960-x

9. Qin L, Jin L, Lu L et al (2011) Naringenin reduces lung metastasis in a breast cancer resection model. Protein Cell 2:507-516. https ://doi.org/10.1007/s13238-011-1056-8

10. Lin WC, Lin JY (2011) Five bitter compounds display different anti-inflammatory effects through modulating cytokine secretion using mouse primary splenocytes in vitro. J Agric Food Chem 59:184-192. https://doi.org/10.1021/jf103581r

11. Mulvihill EE, Allister EM, Sutherland BG et al (2009) Receptor-null mice with diet-induced insulin resistance. Diabetes 58:2198-2210. https://doi.org/10.2337/db09-0634.E.E.M

12. Allister EM, Borradaile NM, Edwards JY, Huff MW (2005) Inhibition of microsomal triglyceride transfer protein expression and apolipoprotein B100 secretion by the citrus flavonoid naringenin and by insulin involves activation of the mitogenactivated protein kinase pathway in hepatocytes. Diabetes 54:1676-1683. https://doi.org/10.2337/diabetes.54.6.1676

13. Kidambi S, Yarmush RS, Novik E et al (2009) Oxygen-mediated enhancement of primary hepatocyte metabolism, functional polarization, gene expression, and drug clearance. Proc Natl Acad Sci 106:15714-15719. https://doi.org/10.1073/pnas.09068 20106

14. Hashimoto T, Ide T (2015) Activity and mRNA levels of enzymes involved in hepatic fatty acid synthesis in rats fed naringenin. J Agric Food Chem 63:9536-9542. https://doi.org/10.1021/acs. jafc.5b03734

15. Fuhr U, Kummert AL (1995) The fate of Naringin in humans: a key to grapefruit juice-drug interactions? Clin Pharmacol Ther 58:365-373. https://doi.org/10.1016/0009-9236(95)90048-9

16. Sánchez-Salgado JC, Castillo-España P, Ibarra-Barajas $M$ et al (2010) Cochlospermum vitifolium induces vasorelaxant and antihypertensive effects mainly by activation of NO/cGMP signaling pathway. J Ethnopharmacol 130:477-484. https://doi. org/10.1016/j.jep.2010.05.037

17. Goldwasser J, Cohen PY, Lin W et al (2011) Naringenin inhibits the assembly and long-term production of infectious hepatitis $C$ virus particles through a PPAR-mediated mechanism. J Hepatol 55:963-971. https://doi.org/10.1016/j.jhep.2011.02.011

18. Nahmias Y, Goldwasser J, Casali M et al (2008) Apolipoprotein B-dependent hepatitis $C$ virus secretion is inhibited by the grapefruit flavonoid naringenin. Hepatology 47:1437-1445. https://doi.org/10.1002/hep.22197

19. Richard AJ, Amini-Vaughan Z, Ribnicky DM, Stephens JM (2013) Naringenin inhibits adipogenesis and reduces 
insulin sensitivity and adiponectin expression in adipocytes. Evid Based Complement Altern Med 2013:1-10. https://doi. org/10.1155/2013/549750

20. Goldwasser J, Cohen PY, Yang E et al (2010) Transcriptional regulation of human and rat hepatic lipid metabolism by the grapefruit flavonoid naringenin: role of PPARa, PPARY and LXRa. PLOS ONE 5:1-9. https://doi.org/10.1371/journal.pone.0012399

21. Jaiswar DR, Jha D, Amin PD (2016) Preparation and characterizations of stable amorphous solid solution of azithromycin by hot melt extrusion. J Pharm Investig 46:655-668. https://doi. org/10.1007/s40005-016-0248-x

22. Kim SJ, Lee HK, Na YG et al (2019) A novel composition of ticagrelor by solid dispersion technique for increasing solubility and intestinal permeability. Int J Pharm 555:11-18. https://doi. org/10.1016/j.ijpharm.2018.11.038

23. Kanaze FI, Kokkalou E, Georgarakis M, Niopas I (2004) A validated solid-phase extraction HPLC method for the simultaneous determination of the citrus flavanone aglycones hesperetin and naringenin in urine. J Pharm Biomed Anal 36:175-181. https:// doi.org/10.1016/j.jpba.2004.05.015

24. Ribeiro IA, Ribeiro MHL (2008) Naringin and naringenin determination and control in grapefruit juice by a validated HPLC method. Food Control 19:432-438. https://doi.org/10.1016/j. foodcont.2007.05.007

25. Ma Y, Li P, Chen D et al (2006) LC/MS/MS quantitation assay for pharmacokinetics of naringenin and double peaks phenomenon in rats plasma. Int J Pharm 307:292-299. https://doi. org/10.1016/j.ijpharm.2005.10.018

26. Liu Y, Ma B, Zhang Q et al (2013) Development and validation of a sensitive liquid chromatography/tandem mass spectrometry method for the determination of raddeanin A in rat plasma and its application to a pharmacokinetic study. J Chromatogr 912:16-23. https://doi.org/10.1016/j.jchromb.2012.09.038

27. Dalagnol M, De BL (2013) Development and validation of a RPHPLC method to quantify naringenin in Lecithin/Chitosan nanoand microparticle suspensions. Lat Am J Pharm 32:2383

28. Khan AW, Kotta S, Ansari SH et al (2015) Self-nanoemulsifying drug delivery system (SNEDDS) of the poorly water-soluble grapefruit flavonoid naringenin: design, characterization, in vitro and in vivo evaluation. Drug Deliv 22:552-561. https:// doi.org/10.3109/10717544.2013.878003

29. Eloy JO, Marchetti JM (2014) Solid dispersions containing ursolic acid in Poloxamer 407 and PEG 6000: a comparative study of fusion and solvent methods. Powder Technol 253:98-106. https ://doi.org/10.1016/j.powtec.2013.11.017

30. Irshad S, Khan IU, Khalid SH et al (2019) Probing the effect of various lipids and polymer blends on clopidogrel encapsulated floating microcarriers. DARU J Pharm Sci. https://doi. org/10.1007/s40199-019-00285-0

31. Pawar J, Tayade A, Gangurde A et al (2016) Solubility and dissolution enhancement of efavirenz hot melt extruded amorphous solid dispersions using combination of polymeric blends: $\mathrm{a} \mathrm{QbD}$ approach. Eur J Pharm Sci 88:37-49. https://doi.org/10.1016/j. ejps.2016.04.001

Publisher's Note Springer Nature remains neutral with regard to jurisdictional claims in published maps and institutional affiliations. 